\title{
Frequency of acute exacerbation of chronic obstructive pulmonary disease in patients taking low dose azithromycin prophylaxis.
}

\footnotetext{
1. MBBS, MRCP

Assistant Professor Medicine Independent Medical College/ Hospital, Faisalabad.

2. MBBS, FCPS

Associate Professor Medicine Independent Medical College/ Hospital, Faisalabad.

3. MBBS

PGR Medicine

Aziz Fatima Hospital, Faisalabad.

4. MBBS, FCPS (Medicine), FCPS (Rheumatology)

Assistant Professor Medicine

Independent Medical College,

Faisalabad.

5. MBBS, FCPS (Medicine)

Associate Professor Medicine Independent Medical College/

Hospital, Faisalabad.

6. MBBS, FCPS (Medicine)

Senior Registrar Medicine

Aziz Fatima Hospital \& Medical

College Faisalabad.
}

Correspondence Address:

Dr. Muhammad Absar Alam

Department of Medicine

Independent Medical College/Hospital

Faisalabad.

absaralam184@hotmail.com

Article received on:

20/08/2019

Accepted for publication:

24/07/2020

\section{INTRODUCTION}

We come across a number of patients having chronic obstructive airway disease (COAD) presented with acute exacerbation in hospitals for multiple times. This not only causes financial burden but also occupy a number of beds in hospitals exhausting various health care facilities as well. Acute exacerbation is also increasing mortality among patients of COAD. Effective treatment of acute symptoms decreases the length of stay in hospital and mortality thereby decreasing financial cost and preserving healthcare facilities. Antibiotics are usually used for acute infective fare-up of COAD. Prophylactic antibiotics can be used to decrease the episodes of acute exacerbations. Macrolides possess
Muhammad Absar Alam1, Muhammad Sarfraz², Arsalan Hafeez ${ }^{3}$, Zafar Ali Zafar ${ }^{4}$, Touseef Anwar ${ }^{5}$, ABSTRACT... Objectives: To assess the frequency of acute exacerbation of chronic obstructive pulmonary disease in patients taking low dose azithromycin prophylaxis. Study Design: Cross Sectional study. Setting: Department of Medicine, Independent University Hospital, Faisalabad. Period: 01-07-2017 to 30-06-2018. Material \& Methods: 100 patients having diagnosis of OPD according to the operational definition were selected from medical opd of hospital after (the patients were followed up for episodes of exacerbations in one year. All acute exacerbation was noted. There was no conflict of interest. Results: Frequency of acute exacerbation of chronic obstructive pulmonary disease was seen in 70 out of $100(70 \%)$ patients aking low dose azithromycin prophylaxis. In female patients frequency of acute exacerbation whose duration of disease was longer. i.e. 7-10 years followed by patients whose duration of disease was 4-6 years (28.6\%) and 1-3 years (25.7\%). Presence of acute dose azithromycin. However literature reported effectiveness of low dose azithromycin for acut exacerbation in patients of COPD. So further study in the form of randomized trail is needed to prove the efficacy of azithromycin.

Key words: $\quad$ Acute Exacerbation, Chronic Obstructive Pulmonary Disease, Low Dose Azithromycin, Prophylaxis. of acute exacerbation of chronic obstructive pulmonary disease in patients taking low dose azithromycin prophylaxis. Professional Med J 2020; 27(11):2438-2444. https://doi.org/10.29309/TPMJ/2020.27.11.4059

both antimicrobial and anti-inflammatory properties. We use low dose of azithromycin as a prophylactic measure in COAD patients to decrease the frequency of acute exacerbation, Since AECOADs is associated with increased inflammation in airways and infections particularly bacterial infections, an effective approach towards the prevention of AECOAD could be the use of prophylactic macrolide treatment.

Currently, two main strategies are used for the prevention of AECOADs. Smoking cessation, influenza vaccination, pulmonary rehabilitation and lung volume reduction surgery is the non-pharmacological approach, Whereas use of inhaled long-acting bronchodilators 
alone or in combination with inhaled corticosteroids, phosphodiesterase-4 inhibitors and $\mathrm{N}$-acetylcysteine and oxygen therapy is pharmacologic approach. ${ }^{6}$

Although acute exacerbations are reduced by 25 $30 \%$ by both the strategies, still approximately one-third COPD patients experience one or more exacerbations every year. ${ }^{7}$

In a study, out of 100 patients, 71 patients were given 500mg azithromycin (usual dose), the rate of event-based exacerbations was 0.59 per patient (59\% in 100 cases). ${ }^{8}$ But one study has reported that low dose azithromycin prophylaxis (250mg) in COPD patients, $50 \%$ developed multiple episodes of acute exacerbation. ${ }^{9}$ Another study has also showed that with low dose (250mg) azithromycin prophylaxis, $47 \%$ subjects had AECOPD within 26 weeks). ${ }^{10}$ This showed that low dose azithromycin has almost equal effect as showed by usual dose.

Rationale of this study is to assess the frequency of acute exacerbation of chronic obstructive pulmonary disease in patients taking low dose azithromycin prophylaxis. Literature shows that azithromycin prophylaxis is used for prevention of AECOPD but not enough results were obtained in literature. So it creates a dispute, whether to rely on azithromycin prophylaxis or not. So we want to conduct this study to assess whether azithromycin is helpful or not in future implementation or some other way should be looked for to prevent the patients from AECOPD. This will help to improve our knowledge and practice and we will be able to recommend the patients to adopt convenient way to prevent AECOPD.

To assess the frequency of acute exacerbation of chronic obstructive pulmonary disease in patients taking low dose azithromycin prophylaxis.

\section{COPD}

It is defined as presence of at least two of following symptoms: dyspnea, cough and or sputum production on most of the days for at least two year.

\section{Acute Exacerbation}

It will be defined as worsening of at least two of the three following symptoms: dyspnea, cough $>3$ attacks per week and sputum production sufficient to warrant a change in therapy.

\section{MATERIAL \& METHODS}

This was a Cross Sectional study, conducted. Department of Medicine, Independent University Hospital, Faisalabad for 12 months (01-07-2017 to 30-06-2018).

Sample size of 100 cases is calculated with $95 \%$ confidence level, $10 \%$ margin of error and taking expected percentage of acute exacerbation of COPD i.e. $50 \%$ with azithromycin prophylaxis.

Non-probability, consecutive sampling techniques used.

\section{SELECTION CRITERIA}

\section{Inclusion criteria}

Patients of 20-80 years age of either gender diagnosed with COPD (as per operational definition)

\section{Exclusion Criteria}

- Patients having bronchial asthma, bronchiectasis, interstitial lung disease, cardiac failure.

- Patients with resting HR>100bpm, a prolonged corrected QT interval (>450 msec) or using medications that prolong the QTC interval

100 patients fulfilling the criteria as mentioned in operational definition, were selected from medical OPD of hospital, Department of Medicine, Independent University Hospital, Faisalabad. After taking consent from the patients and ethical committee of the hospital, demographic details (name, age, gender, BMI and duration of COPD) were obtained. Then all patients were given 250mg oral azithromycin thrice weekly for 12 months. All patients were instructed to report if they feel any change in their symptoms regarding cough, dyspnea and sputum. History was taken from all the patients about number of acute 
exacerbation in the past year as per operational definition. Number of acute exacerbations in last year were noted. All data was noted on proforma.

IBM SPSS version 21 was used for entry and analysis of data. All quantitative variables like age, BMI, duration of COPD and episodes of acute exacerbation were presented in the form of mean and standard deviation. All qualitative variables like gender and acute exacerbation of COPD were presented in the form of frequency and percentage. Data was stratified for age, gender, BMI, episodes of acute exacerbation and duration of COPD. Chi-square test was applied to compare the acute exacerbation of COPD in stratified groups. P-value of $<0.05$ was taken as significant.

\section{RESULTS}

Mean age of patients in this study was $49.05 \pm 17.29$ years. Minimum and maximum age of patients was 20 and 79 years respectively. (Table-I)

There were $40(40 \%)$ male and 60(60\%) female patients in the study population. (Figure-1)

Mean body mass index of patients was 20.95 \pm 1.45 . (Table-II)

Mean duration of COPD was $6.02 \pm 2.89$ years. Minimum and maximum duration of COPD was 1 and 10 years respectively. (Table-III)

There were 32(32\%) patients who had 1-2 episodes of acute exacerbation of COPD, $30(30 \%)$ patients had 3-4 episodes, 19(19\%) had 5-6 episodes and $19(19 \%)$ patients had 7-8 episodes of acute exacerbation of COPD. (Table-IV).

There were $30(30 \%)$ patients who had no episode of acute exacerbation of COPD within 12 months' time period, however 22(22\%) patients had 1-2 episode, 18(18\%) patients had 3-4 episode and $30(30 \%)$ patients had 5-6 episodes of acute exacerbation of COPD within 12 months' time period (Table-V).

There were $70(70 \%)$ patients who had one or more episode of acute exacerbation of COPD.
(Figure-2)

Highest frequency of acute exacerbation of COPD was seen in the age group $>60$ years (28.6\%), followed by $20 \%$ each in age group 31 40 and $41-50$ years, followed by $17.1 \%$ in $51-60$ years and $14.3 \%$ in patients with age in between 20-30 years. As per this trend no statistically significant association was seen between age of patients and acute exacerbation of COPD. i.e. (p-value $=0.899)$. (Table-VI). All 70(100\%) patients with acute exacerbation of COPD had normal body mass index. (Table-VII).

Among diagnosed patients with acute exacerbation of COPD 26(37.1\%) were male and $44(62.9 \%)$ were females. Although female's patients were greater than male patients still no statistically significant association was seen between acute exacerbation of COPD and gender of patients. i.e. ( $p$-value=0.373) (Table-VIII).

Highest frequency of acute exacerbation of COPD was seen in patients whose duration of COPD was $7-10$ years i.e. $45.7 \%$, followed by $28.6 \%$ in patients whose duration of disease was 4-6 years and the lowest frequency of acute exacerbation was seen in patients whose duration of COPD was 1-3 years. As per this trend no statistically significant association was seen between acute exacerbation and duration of COPD. i.e. $(p-$ value $=0.773)($ Table-IX).

Among the diagnosed patients of acute exacerbation of COPD there were 11(15.7\%) patients who had 1-2 acute exacerbation episodes, $26(37.1 \%)$ had $3-4$ episodes, $16(22.9 \%)$ had 5-6 episodes and $17(24.3 \%)$ had $7-8$ episodes of acute exacerbation. As per this trend statistically significant association was seen between acute exacerbation and number of episodes of acute exacerbation of COPD. i.e. $\quad(p-v a l u e=0.000)$ (Table-X).

\begin{tabular}{|c|c|}
\hline 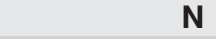 & 100 \\
\hline Mean & 49.05 \\
\hline SD & 17.299 \\
\hline Min & 20 \\
\hline Max & 79 \\
\hline
\end{tabular}




\begin{tabular}{|l|c|}
\hline \multicolumn{1}{|c|}{$\mathbf{N}$} & $\mathbf{1 0 0}$ \\
\hline Mean & 20.950 \\
\hline SD & 1.4504 \\
\hline Min & 18.5 \\
\hline Max & 23.4 \\
\hline
\end{tabular}

Table-II. Descriptive statistics for body mass index of patients.

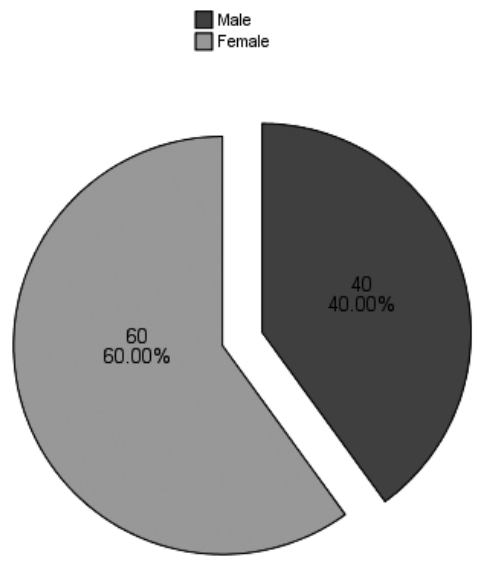

Figure-1. Gender distribution of patients.

\begin{tabular}{|l|c|}
\hline \multicolumn{1}{|c|}{} & $\mathbf{1 0 0}$ \\
\hline Mean & 6.02 \\
\hline SD & 2.892 \\
\hline Min & 1 \\
\hline Max & 10 \\
\hline
\end{tabular}

Table-III. Descriptive statistics for duration of COPD.

\begin{tabular}{|l|c|c|}
\hline \multicolumn{1}{|c|}{ Episodes } & Frequency & Percentage \\
\hline $1-2$ & 32 & $32.0 \%$ \\
\hline $3-4$ & 30 & $30.0 \%$ \\
\hline $5-6$ & 19 & $19.0 \%$ \\
\hline $7-8$ & 19 & $19.0 \%$ \\
\hline Total & 100 & $100 \%$ \\
\hline
\end{tabular}

Table-IV. Frequency distribution for Episodes of acute exacerbation in past year.

\begin{tabular}{|c|c|c|}
\hline Episodes & Frequency & Percentage \\
\hline None & 30 & $30.0 \%$ \\
\hline $1-2$ & 22 & $22.0 \%$ \\
\hline $3-4$ & 18 & $18.0 \%$ \\
\hline $5-6$ & 30 & $30.0 \%$ \\
\hline Total & 100 & $100 \%$ \\
\hline
\end{tabular}

Table-V. Frequency distribution for Episodes of acute exacerbationwithin 12 months. 


\begin{tabular}{|c|c|c|c|}
\hline & \multicolumn{2}{|c|}{ Acute Exacerbation } & \multirow{2}{*}{ Total } \\
\hline & Present & Absent & \\
\hline $1-3$ & $18(25.7 \%)$ & $7(23.3 \%)$ & 25 \\
\hline $4-6$ & $20(28.6 \%)$ & $7(23.3 \%)$ & 27 \\
\hline $7-10$ & $32(45.7 \%)$ & $16(53.3 \%)$ & 48 \\
\hline Total & 70 & 30 & 100 \\
\hline \multicolumn{4}{|c|}{$\begin{array}{c}\text { Table-IX. Association of acute exacerbation with } \\
\text { duration of COPD. }\end{array}$} \\
\hline & \multicolumn{2}{|c|}{ Acute Exacerbation } & \multirow{2}{*}{ Total } \\
\hline & Present & Absent & \\
\hline $1-2$ & $11(15.7 \%)$ & $21(70 \%)$ & 32 \\
\hline $3-4$ & $26(37.1 \%)$ & $4(13.3 \%)$ & 30 \\
\hline $5-6$ & $16(22.9 \%)$ & $3(10 \%)$ & 19 \\
\hline $7-8$ & $17(24.3 \%)$ & $2(6.7 \%)$ & 19 \\
\hline Total & 70 & 30 & 100 \\
\hline \multicolumn{4}{|c|}{$\begin{array}{l}\text { Table-X. Association of acute exacerbation with } \\
\text { episodes of acute exacerbation in past year. }\end{array}$} \\
\hline
\end{tabular}

\section{DISCUSSION}

Acute exacerbations causing significant effects in terms of reduced quality of life, a more rapid decline in lung function, and an increased risk of death. ${ }^{11-13}$ Patients with COPD may still have on average 1.4 episodes of acute exacerbation each year despite receiving inhaled steroids, long-acting beta2 -agonists, and long-acting muscarinic antagonists. All above drugs decrease the frequency of acute exacerbation.9,14

The exact mechanism of action of macrolides is unknown, but some studies showing the immune-modulatory and physiological properties of macrolides. ${ }^{15}$

Recently, it has been shown that erythromycin and azithromycin, when added to usual therapy prevent exacerbations in patients with chronic obstructive pulmonary disease (COPD), a predominantly neutrophilic airway disease. ${ }^{16,17,18}$

In this study frequency of acute exacerbation of chronic obstructive pulmonary disease was seen in $70(70 \%)$ patients taking low dose azithromycin prophylaxis. The highest frequency of acute exacerbation of COPD was seen in the age group $>60$ years $(28.6 \%)$, followed by in the age group
$31-50$ years (40\%), 51-60 years (17.15) and 2030 years $(14.3 \%)$ respectively. (P-value $=0.899)$ In female patients frequency of acute exacerbation of COPD was high as compared to male patients. i.e. $62.9 \%$ vs. $37.1 \%$, p-value $=0.373$. Frequency of acute exacerbation of COPD was higher in patients having longer duration of disease i.e. 7-10 years followed by patients whose duration of disease was 4-6 years (28.6\%) and 1-3yrs (25.7\%). (P-value $=0.773)$ Presence of acute exacerbation of COPD was significantly associated with episodes of acute exacerbation in past. ( $P$-value $=0.000)$. Highest frequency of acute exacerbation was seen in patients who had 3-4 episodes.

Richard K. Albert in his study reported that in azithromycin group the frequency of exacerbations of COPD was 1.48 exacerbations per patient-year, whereas in placebo group it was 1.83 per patient-year in $(p$-value $=0.01)$. In azithromycin group, the hazard ratio for having an acute exacerbation of COPD per patient-year in was $0.73(95 \% \mathrm{Cl}, 0.63$ to $0.84 ; \mathrm{P}<0.001) .^{9}$

Study conducted by Guy G Brusselle reported that, $26(47 \%)$ subjects had an episode of acute exacerbation of COPD in azithromycin group, whereas $26(48 \%)$ had an episode of AECOPD in the placebo group (relative risk $0.98,95 \% \mathrm{Cl} 0.68$ to $1.43, p=1.000) .{ }^{19}$

Xavier Pomares studied the effect of longterm intermittent azithromycin therapy on reduction of the frequency of exacerbation in severe chronic obstructive pulmonary disease (COPD). Compared with baseline data significant reduction in the number of AECOPD was noted with azithromycin therapy $(2.8 \pm 2.5$ versus $6.8 \pm$ 2.8, p-value, 0.001). ${ }^{4}$

Above studies have reported the efficacy of azithromycin for prevention of acute exacerbation of COPD. But in this study prophylaxis of azithromycin showed high frequency of acute exacerbation of COPD. This may be due the difference in dose of azithromycin given to the patients, duration of therapy and other patient related and methodological considerations. The 
design of this study is prospective however the above mentioned studies were randomized controlled trials. This is also an important difference which might be the cause of this dispute.

Metabolism of azithromycin does not interfere with the metabolic pathway of cytochrome P450, thus avoiding possible metabolic interference with other drugs often used in COPD which share the same pathway, such as steroids and theophylline. It has better gastrointestinal tolerance and less hepatotoxicity, and has a better safety profile in long-term use as it is not associated with long QT syndrome. ${ }^{20}$

Azithromycin has greater bacteriological and clinical activity as compared to other macrolides. ${ }^{21}$ Giventhe deleterious effects ofacute exacerbations of COPD with respect to morbidity and mortality, adding azithromycin to the treatment regimen of patients who have had an acute exacerbation of COPD within the previous year or who require supplemental oxygen is a valuable option.

\section{CONCLUSION}

Results of this study showed a high frequency of acute exacerbation in patients of COPD even with the prophylaxis of low dose azithromycin. However literature reported effectiveness of low dose azithromycin for acute exacerbation in patients of COPD. So further study in the form of randomized trial is needed to prove the efficacy of azithromycin.

Copyright@ 25 July, 2020.

\section{REFERENCES}

1. Spagnolo P, Fabbri LM, Bush A. Long-term macrolide treatment for chronic respiratory disease. European Respiratory Journal 2013; 42(1):239-51.

2. Suissa $S$, Dell'Aniello $S$, Ernst P. Long-term natural history of chronic obstructive pulmonary disease: severe exacerbations and mortality. Thorax 2012; 67(11):957-63.

3. Hurst J, Vestbo J, Anzueto A, Locantore N, Müllerova H, Tal-Singer R, et al. Evaluation of COPD longitudinally to identify predictive surrogate endpoints (ECLIPSE) investigators susceptibility to exacerbation in chronic obstructive pulmonary disease. N Engl J Med
2010; 363(12):1128-38.

4. Pomares X, Montón C, Espasa M, Casabon J, Monso E, Gallego M. Long-term azithromycin therapy in patients with severe COPD and repeated exacerbations. Int J Chron Obstruct Pulmon Dis 2011; 6(2):449-56.

5. Ni W, Shao X, Cai X, Wei C, Cui J, Wang R, et al. Prophylactic use of macrolide antibiotics for the prevention of chronic obstructive pulmonary disease exacerbation: A meta-analysis. PloS one 2015; 10(3):e0121257.

6. Marchetti N, Criner GJ, Albert RK. Preventing acute exacerbations and hospital admissions in COPD. CHEST Journal 2013; 143(5):1444-54.

7. Vestbo J, Edwards LD, Scanlon PD, Yates JC, Agusti A, Bakke $P$, et al. Changes in forced expiratory volume in 1 second overtime in COPD. New England Journal of Medicine 2011; 365(13):1184-92.

8. Wong C, Jayaram L, Karalus N, Eaton T, Tong C, Hockey $\mathrm{H}$, et al. Azithromycin for prevention of exacerbations in non-cystic fibrosis bronchiectasis (EMBRACE): A randomised, double-blind, placebo-controlled trial. The Lancet 2012; 380(9842):660-7.

9. Albert RK, Connett J, Bailey WC, Casaburi R, Cooper Jr JAD, Criner GJ, et al. Azithromycin for prevention of exacerbations of COPD. New England Journal of Medicine 2011; 365(8):689-98.

10. Brusselle GG, VanderStichele C, Jordens P, Deman $\mathrm{R}$, Slabbynck $\mathrm{H}$, Ringoet $\mathrm{V}$, et al. Azithromycin for prevention of exacerbations in severe asthma (AZISAST): A multicentre randomised double-blind placebo-controlled trial. Thorax 2013;68(4):322-9

11. Tsai CL, Sobrino JA, Camargo Jr CA. National study of emergency department visits for acute exacerbation of chronic obstructive pulmonary disease, 1993-2005. Academic Emergency Medicine 2008; 15(12):1275-83.

12. Donaldson G, Seemungal T, Bhowmik A, Wedzicha $J$. Relationship between exacerbation frequency and lung function decline in chronic obstructive pulmonary disease. Thorax 2002; 57(10):847-52.

13. Soler-Cataluna J, Martínez-García MÁ, Sanchez PR, Salcedo $E$, Navarro M, Ochando R. Severe acute exacerbations and mortality in patients with chronic obstructive pulmonary disease. Thorax 2005; 60(11):925-31. 
14. Aaron SD, Vandemheen $\mathrm{KL}$, Fergusson D, Maltais Fo, Bourbeau J, Goldstein R, et al. Tiotropium in combination with placebo, salmeterol, or fluticasonesalmeterol for treatment of chronic obstructive pulmonary disease: A randomized trial. Annals of internal medicine 2007; 146(8):545-55.

15. Cameron EJ, McSharry C, Chaudhuri R, Farrow S, Thomson N. Long $\square$ term macrolide treatment of chronic inflammatory airway diseases: Risks, benefits and future developments. Clinical \& Experimental Allergy 2012; 42(9):1302-12.

16. Seemungal TA, Wilkinson TM, Hurst JR, Perera WR, Sapsford RJ, Wedzicha JA. Long-term erythromycin therapy is associated with decreased chronic obstructive pulmonary disease exacerbations. American journal of respiratory and critical care medicine 2008; 178(11):1139-47.

17. Brusselle GG, Joos GF, Bracke KR. New insights into the immunology of chronic obstructive pulmonary disease. The Lancet 2011; 378(9795):1015-26.
18. Criner GJ, Bourbean J, Diekemper RL, et al. Prevention of acute exacerbation of COPD; American college of chest physicians and Canadian thoracic society guidelines. Chest. 2015; 147:894-942.

19. Brusselle GG, Vander Stichele C, Jordens P, Deman $R$, Slabbynck $H$, Ringoet $V$, et al. Azithromycin for prevention of exacerbations in severe asthma (AZISAST): A multicentre randomised doubleblind placebo-controlled trial. Thorax 2013: thoraxjnl-2012-202698.

20. Huang $\mathrm{BH}$, WU $\mathrm{CH}, \mathrm{HSIA} \mathrm{CP}$, YIN CHEN C. Azithromycin $\square$ Induced Torsade De Pointes. Pacing and Clinical Electrophysiology 2007; 30(12):1579-82.

21. Martinez FJ, Curtis JL, Albert R. Role of macrolide therapy in chronic obstructive pulmonary disease. Int J Chron Obstruct Pulmon Dis 2008; 3(3):331-50.

\begin{tabular}{|c|c|c|c|}
\hline \multicolumn{4}{|c|}{ AUTHORSHIP AND CONTRIBUTION DECLARATION } \\
\hline Sr. \# & Author(s) Full Name & Contribution to the paper & Author(s) Signature \\
\hline 1 & M. Absar Alam & Data collection. & $a n$ \\
\hline 2 & Muhammad Sarfraz & Data analysis. & \\
\hline 3 & Arsalan Hafeez & Compilation of resutls & \\
\hline 4 & Zafar Ali Zafar & Discussion & \\
\hline 5 & Touseef Anwar & Review. & \\
\hline 6 & Muhammad Rizwan & Review. & \\
\hline
\end{tabular}

